\section{Publish abstracts}

SIR - J.R. Metcalf (Nature 15 March, p.222) asks whether abstracts should be included in hard copy and computerized databases. If something is published or recorded, whatever its merit or scientific value, it is essential that the bibliographic control exists to identify and find it.

I, for one (as a librarian and information scientist), would totally support, and indeed use, any secondary source of information that included the coverage of abstracts of this nature, as well as full papers appearing in conference proceedings.

MRC Clinical and Population

SHEILA M. MOULD

Cytogenetics Unit,

Western General Hospital,

Edinburgh EH4 $2 X U$, UK

SIR - Many databases such as Biological Abstracts include abstracts of papers presented at conferences. The range of quality of these abstracts (as indeed with full papers) is large, but as a database user in the pharmaceutical industry, I have found many occasions when the first announcement of a new drug is through such publication. Consequently I fully support their inclusion in computerized databases.

In BIOSIS (Biological Abstracts) it is a simple matter to exclude all such abstracts, if desired, since they appear in the "Register of Research Methods" section of that database. In other databases it is of ten easy to identify such abstracts because they are normally only a single page in length, or they may appear in a proceedings supplement with annotated pagination. A competent database searcher can therefore avoid inundating the researcher with such material if requested.

Surely on balance it is better to have such abstracts included and sift out the unwanted material than to proceed with research in ignorance of related and potentially important information.

I. MCFARLANE

Organon Laboratories Limited,

Newhouse,

Lanarkshire ML1 SSH, UK

\section{No simple answer}

SIR - Jeremy Bray (Nature 1 March, p.9) says that "a reduction of salt, sugar and saturated fatty acids and an increase of dietary fibre in the diet of the nation would substantially reduce mortality and improve health in the middle years of life"'. This talismanic theory was propounded a few years ago by Senator George McGovern. It is an illustration of "Mencken's law", which states "For every complex problem, there is a simple solution, and it is wrong"'. Nations do not eat diets, individuals eat diets. You cannot determine individual intake by dividing total consumption by number of people. Too much salt, sugar or fats, or even too much water, are unhealthy for an individual, but salt, sugar and fats are basic nutrients. There is debate as to whether excesses of unsaturated fatty acids are actually more harmful than are excesses of saturated fatty acids. "Fibre" is a variable entity. It is sometimes measured as "crude fibre" by weighing residues of foodstuffs after extracting with ether, dilute acid and dilute alkali ${ }^{1}$. It is also described as a mixture principally of cellulose, hemicellulose, lignin, pectin and gums that is not digested in the intestinal tract ${ }^{2}$. "Fibre" is now so fashionable that the addition of sawdust to bread in the United States was recently proposed, which would be great for termites.

Non-smokers and non-drinkers who eat lots of meat and sugar are said to live longer than the average person ${ }^{3}$. Salt intake needs to be reduced in susceptible individuals who consume excessive quantities, rather than "in the diet of the nation". Food should be eaten in variety and in moderation, and enjoyed. THOMAS H. JUKES Department of Nutritional Sciences, University of California, Berkeley, Oakland, California 94608, USA 1. Composition of Foods, Agriculture Handbook No.8
(USDA, Washington, 1963).

2. Story, J.A. \& Kritchevsky, D. in Biochemistry of Nutrition, 189-206 (University Park Press, Baltimore, 1979).

3. Herbert, V. National Forum, Phi Kappa Phi Journal, Winter 1984, pp.3-7.

\section{The fly domesticated}

SIR - Undoubtedly the method of F.E.G. $\mathrm{Cox}^{1}$, permitting flies to be trapped (rather than swatted) is kind. Yet the problem of what to do with the captured fly remains. Since the intent is to avoid killing the fly, only two options present themselves: (1) release the fly out of doors or (2) contain it in a "flyhouse" in part of the home or laboratory. The second option is lamentably untenable in view of the fact that the flies thus adopted would, given adequate nourishment, soon yield a host of young, requiring frequent expansion of their domicile. The first option is therefore the only acceptable course but can result in tragedy if practised during the winter season when outdoor temperatures frequently drop below freezing. In such a climate, releasing the fly out of doors would, in a high percentage of cases, lead to its death due to exposure to the cold ${ }^{2}$ (flies are poikilothermic).

A partially acceptable solution to the dilemma was suggested to me by A.S. Glass: if the fly is released at the boundary between indoors and out, at the window sill by an opened window, for example, the fly may leave the room spontaneously. If, on the other hand, it returns to the room it may be recaptured and again released, the process being repeated indefinitely (with suitable rest periods between trials) or until satisfaction is achieved. Such "encouraged suicide" was long accepted, in order to permit the survival of some members of the group, among some ${ }^{3}$ although not all ${ }^{4}$ traditional human societies living in correspondingly harsh climates.
Interestingly, nobody ${ }^{1,5-7}$ has yet suggested the possibility of coexistence. The fly is a most intriguing creature. It is small and requires virtually no care, yet will literally eat from one's hand. It thus has many of the attributes of a fine house pet.

KENNETH L. BELL

Department of Chemistry,

New York University,

4 Washington Place,

New York, New York 10003, USA

1. Cox, F.E.G. Nature 307, 8 (1984).

2. Detheir, V.G. To Know a Fly, 23 (Holden-Day, New York, 1962).

3. Freuchen, P. Book of the Eskimos, 194-206 (World Publishing Co., 1961).

4. Vanstone, J.W. Point Hope, an Eskimo Village in Transition (University of Washington Press, 1962).

. Gray, E.G. Nature 304, 678 (1983).

6. Miller, A. Nature 305, 664 (1983).

7. Kruythoff, P.N. Nature 305,570 (1983).

\section{Count is OK}

SIR - R. F. Entwistle (Nature 308, 222; 1984 ) is supporting a lost cause in opposing the use of the "count" as a pseudo-unit. Language changes with use, and radioactivity "counts" made the transition from "lab-speak" to the respectability of regular appearance on the pages of biochemical literature at least 30 years ago.

For a long time this editorial office tried to persuade authors writing for its journals that "to fast", as an intransitive verb, was incorrectly used in expressions such as "fasted rats". The latest supplement to the Oxford English Dictionary reveals the influence of biologists on grammar; "to fast" now receives recognition as a transitive verb, with the usage sanctioned by quotations from your own distinguished pages.

TONY EVANS

Editorial Office,

The Biochemical Society,

7 Warwick Court,

London WCIR SDP, UK

\section{Pagiarism claim}

SIR - It is well known that plagiarism or appropriation of ideas or passages from another work or author exists in the scientific community today. Another, contrasting practice exercised by an alarming proportion of authors submitting papers today is the wilful omission of references to previous work in the specific subject. By doing so not only do they pretend that their work or idea/s is/are original but also deceive the referees and the peers who, unfortunately, may be unable to keep up with the explosive growth of information which we witness today. As there is no specific word in the English language to describe this practice I wish to suggest the word $P A$ giarism to denote Purposeful $A$ voidance of making references to past literature or ideas with intention of deceiving the community, at large.

LAKSHMANP. SAMARANAYAKE Glasgow Dental Hospital and School, 378 Sauchiehall Street,

Glasgow G2 3JZ, UK 